\title{
Multidisciplinary Approach in Breast Cancer
}

Ana Maria de Araujo Martins ${ }^{1}$, Eliza Maria de Freitas Rangel${ }^{1}$, Kelly Cristina Reis ${ }^{1}$, Ana Silvia Diniz Makluf ${ }^{2}$, Soraia Martins de Araujo ${ }^{3}$, Carolina de Oliveira Barra ${ }^{4}$, Priscilla Duraes Bicalho ${ }^{4}$, Alexandre de Almeida Barra*5,6, Aloma de Fatima Campos Morici ${ }^{5}$, Annamaria Massahud Rodrigues dos Santos ${ }^{5}$, Ana Cristina Dias de Paiva ${ }^{5}$, Cristóvão Pinheiro Barros ${ }^{5}$, Debora Balabram ${ }^{5}$, Gilvane Naves Marcondes Goulart ${ }^{5}$, Larissa Oliveira de Aquino ${ }^{5}$, Mayne Cardoso Cani ${ }^{5}$, Thais Vilela de Pinho Andrade ${ }^{5}$, Carolina Patricia Mendes Rutkowski ${ }^{7}$, Leandro Alves Gomes Ramos ${ }^{7}$ and Juliana Silva Barra ${ }^{8}$

${ }^{1}$ Department of Nursing, Instituto da Previdência dos Servidores de Minas Gerais, Belo Horizonte, Brazil

${ }^{2}$ Department of Physiotherapy, Instituto da Previdência dos Servidores de Minas Gerais, Belo Horizonte, Brazil

${ }^{3}$ Department of Social Work, Instituto da Previdência dos Servidores de Minas Gerais, Belo Horizonte, Brazil

${ }^{4}$ Department of Psychology, Instituto da Previdência dos Servidores de Minas Gerais, Belo Horizonte, Brazil

${ }^{5}$ Department of Breast Surgery, Instituto da Previdência dos Servidores de Minas Gerais, Belo Horizonte, Brazil

${ }^{6}$ Department of Surgery, Gynecology and Obstetrics and Propedeutic, Universidade Federal de Ouro Preto, Ouro Preto, Brazil

${ }^{7}$ Department of Oncology, Instituto da Previdência dos Servidores de Minas Gerais, Belo Horizonte, Brazil

${ }^{8}$ Department of Gynecology and Obstetrics, Universidade Federal de Minas Gerais, Belo Horizonte, Brazil

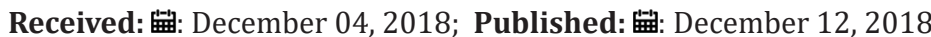

*Corresponding author: Alexandre de Almeida Barra, Department of Breast Surgery of IPSEMG, Member of the Department of Surgery, Gynecology and Obstetrics and Propedeutics of the Federal University of Ouro Preto, Brazil

Abstract

Breast cancer is the most common neoplasm among women. Worldwide, there will be about 2.1 million newly diagnosed female breast cancer cases in 2018, accounting for almost 1 in 4 cancer cases among women. The disease is the most frequently diagnosed cancer in the vast majority of the countries.

The purpose of this article is to report the positive experience of a multidisciplinary team in the care of women with breast cancer and their family members. Our approach that is part of the Cancer Patient Support Center (CPSC) at the public health (IPSEMG) in Brazil has been developed taking into account a broader concept of health care. We value not only individual dimensions in patient care, but also common ones, we recognize the importance of dealing with non-biological aspects of the disease, such as socioeconomic, political and cultural facets and our service is focused on health promotion rather than merely on curative treatment. Among the advantages of our approach, we highlight the facilitated accessibility to health services, the patient-centered communication and shared decision making, and the strong bonds between health professionals, patients, and family members. As part of CPSC's activities, we emphasize the services provided by "Aconchego" ("Warmth"), that is our breast cancer support group at public health in Brazil.

Keywords: Breast Cancer; Team; Support Group

\section{Introduction}

Breast cancer is the most common neoplasm among women. Worldwide, there will be about 2.1 million newly diagnosed female breast cancer cases in 2018, accounting for almost 1 in 4 cancer cases among women. The disease is the most frequently diagnosed cancer in the vast majority of the countries [1].

There are many determinants of health and are also many determinants of cancer, the human being is also plural and precisely for these reasons the importance of an interdisciplinary, collective work with breast cancer women and their relatives is reinforced. The impacts of cancer diagnosis and treatment can directly interfere with the individual's lifestyle [2] and the negative effects of breast cancer can affect patient's quality of life well beyond the end of treatment [3]. Providing patients and their families with comprehensive information and exchanging experiences teaching the best ways to deal with the problems arising from the disease are 
objectives of specialized services in the treatment of breast cancer [3].

Considering breast cancer which always requires policies and referrals based on up-to-date and real knowledge, it was decided to perform this work whose objective is show the work of Cancer Patient Support Center (CPSC) at the public health (IPSEMG) in Brazil, associated with a positive experience of a multidisciplinary team called "Aconchego" ("Warmth").

\section{Method}

After medical evaluation and upon confirmation of the diagnosis of cancer, the patients are referred to CPSC and from that moment all the necessary procedures and referrals for the treatment are performed. The objective was to provide targeted care for patients diagnosed with breast cancer. The reception is made by nurses qualified and experienced in this activity for more than 15 years, in order to show the patient that she is not alone in this journey.

CPSC carries out strategies for the treatment of breast cancer, in compliance with law in Brazil which establishes sixty days for the user to start treatment after diagnosis. After the reception, CPSC nurses and secretaries provide patients with access to treatment through various actions, such as scheduling surgery, radiotherapy, chemotherapy, social worker, physiotherapy and psychology.

This differentiated care, with a multidisciplinary approach, makes patients and families feel more prepared to face the situations generated by the disease. Within the actions of the CPSC, there is a team called "Aconchego" ("Warmth"), and that had the name chosen by the patients themselves. Weekly, the team promotes meetings with patients. The primary challenge is to facilitate the reintegration of each patient. In order to do this, it receives reception and guidance to improve self-esteem and sociability. The team seeks to emphasize the integrated actions developed by the professionals so that effective communication between them is established and for the patients to feel protected. In all the meetings, in the first moment, there is a reception of the new patients who describe their history and what expectation concerning the group and treatment.

In addition to lectures on various topics, workshops, and special day celebrations are promoted. Professionals are also aware that, often, the lack of information is a cause of suffering, abandonment of treatment or even wrong attitudes during the evolution of treatment. Responding to the doubts and exchanging experiences concerning the disease, contributes to the improvement of the quality of life of the patients and also of their families.

The support group meetings are with patients, family members, volunteers, graduate and post-graduate students and health professionals. In all meetings, knowledge about the disease is also built on the experiences of these women concerning breast cancer. Eventually, other health professionals are invited to attend the meeting and advise on topics proposed by the group. Volunteers are also invited by the patients themselves and by the health professionals to contribute with activities such as dance, group dynamics and celebrate commemorative dates. Leisure activities are also proposed, visiting museums and theaters. These activities have an important character, since it centralizes actions in the living, leisure and pleasant activities and not only in the disease.

Physiotherapy plays a vital role in the care and treatment of adverse effects of treatment. In the support group, the physiotherapist besides guiding the care with the upper limb homolateral to the surgery, proposes groups of exercises focusing on body awareness, relaxation, muscle strengthening, and respiratory exercises. These guidelines are important because it prevents posttreatment complications, including lymphedema. When necessary, or in the presence of post-treatment complications, the patients are referred for individualized outpatient physiotherapeutic care. Patients are invited to participate in a group of exercises once a week supervised by physiotherapist and are encouraged to exercise for at least two more hours throughout the week, totaling 150 minutes of aerobic physical activity as per the American Cancer Society guidelines [4].

The social service has a function of welcoming, listening, bonding and accountability to the demands presented, democratizing information about community resources, patients' rights and access to health services. Information regarding the rights of cancer patients is made available during meetings. The nurses, besides receiving the patients, provides guidance on pre and post-operative care and performs group dynamics that allow reflection on themes such as sexuality, aesthetics, lived losses, death, among others. Psychology acts alongside the group mediating conflicts, discuss the specific demands of each woman and family individually, contributing to the emotional strengthening, adherence to the treatment program and expanding the coping strategies of these women in the face of breast cancer. Appropriate techniques are used such as relaxation, verbalizations, perceptions of what is currently happening.

\section{Results}

CPSC started its activities in March 2014, and 6861 consultations were already carried out. The demand for the service grows every year in great proportion, this reinforces the quality and importance of this support nucleus. The professionals, responsible for the reception, explain to the patient the effect of this diagnosis and how the treatment will be.

The work performed by the support nucleus is reflected in the satisfaction of the users, the health team works with more safety and comfort since the difficulties of patients access to consultations, exams and treatment are minimized. The time between diagnosis and initiation of treatment is shorter. This ensures greater agility, quality, and satisfaction of the patients and the team of professional's care. Working in multidisciplinary team help to recognize a patient's need and to maintain good communication in a climate of respect among all team members. Breast cancer treatment can be very stressful, and through good communication and informed involvement from all team members, patient motivation remains high. 


\section{Discussion}

CPSC has been shown to be an essential tool in the care of women with breast cancer since it facilitates access to health services. The group creates a greater bond with the user and not only with the disease. The bond expands to the dimension of the social, cultural, economic, political subject and not just to the biological subject. The autonomy of the subject is continuously encouraged.

Although working with support groups is common in health services, in the literature we find few references that demonstrate the effectiveness of this type of intervention. Bjöneklett et al. [5] showed through a randomized trial the work done in a support group. A total of 392 patients were divided into two groups: one control group and another intervention group. This intervention group received orientation, relaxation training, and mental visualization exercises. Both groups showed improvement of symptoms and fatigue over time, but there was no difference between the support group and the control group regarding the quality of life [5]. This study reinforces the difficulty that health professionals have to demonstrate the beneficial effect of the support group over time, but the team realizes that the patient who has adherence, participation in the support group, shows more safety, reliability, acceptance and more serenity throughout her treatment [5].

The methodology used in the support group is also documented in other centers that use a support group as an aid in coping with the disease. Health professionals encourage patients to tell the story of their illness as a coping strategy for fear of death, to learn to control emotions such as anger and revolt after diagnosis. Studies have shown that the support group is considered effective psychotherapy for patients with disease, probably by the existential and collective focus of the disease [6].

The literature has shown that physical activity plays a fundamental post-treatment role in breast cancer, decreasing mortality rates and recurrence of the disease in these women [79]. The CPSC has emphasized the importance of the practice of physical activity. Exercise improves mood, decreases depression, and improves quality of life [9].

Lack of information and knowledge of the disease are manifested in the patients difficulty in talking about cancer. The availability of information is an essential tool in the process of coping with the disease. When the patient knows what the therapeutic possibilities are, this bring comfort and safety to her and family. The family, if not well oriented, does not know how to act in the face of the disease, so the family's participation in the group and the meetings are encouraged. Family support is necessary because the family feels welcomed by the staff and the institution.

Some support group encourage the patients' families or friends to attend their meetings [10]. One study found that while the involvement of breast cancer patients in support group meetings was supported by $93 \%$ of patient advocates, only a minority of health care professionals (32\% of surgeons, $25 \%$ of medical oncologists, and $24 \%$ of radiation oncologists) supported the idea, mainly because they felt that it would raise patient anxiety [11]. However, a pilot study involving breast cancer patients concluded that patient attendance in support group meetings is potentially acceptable to patients and health care professionals, without significantly raising patient anxiety [12]. The professional of support group must be re-educated in their humanity, again arousing the feelings of humanism, of compassion, of the priesthood in the broader sense of the term, in order to make care cease to be just a technique and become an art as well [13].

The search for necessary care is based on the reorganization of professional practices and the reformulation of health teams. The reference team that is composed of a group of professionals translates the idea of interdisciplinary. We focus on the idea of being all collaborators, expanding our horizons with indirect benefit to the object of our action. The work of the team comprises different professionals with different but integrated functions. Establishing effective communication among these professionals is fundamental to the maintenance of human dignity. In contemporary practice, breast cancer patient care requires the expertise of a wide range of specialists, and effective communication among them is crucial to formulate an optimal treatment strategy [14].

The breast cancer patient often has difficulties to deal with the diagnosis. At that moment, nurses play a fundamental role in the reception, listening, and guidance of this patient. Nurses are a key point of contact between oncologists and patients and are critical for the continuity of care of breast cancer patients, thus their attendance in support group in an increasing frequency is desirable $[10,15]$. We observed that patients who assiduously participate in this group have more facilities in dealing with the anxieties, traumas, and fears caused by the disease.

\section{Conclusion}

Breast cancer is a complex disease that has a social, functional and psychological impact. Given these factors, we emphasize the importance of its approach from a multidisciplinary perspective. This approach allows the treatment not only of biomedical aspects but also of the impact of the disease in a perspective that considers functional aspects, activity and social participation, mediated by the environmental and individual aspects of the patients, which are fundamental in the promotion and treatment.

We hope that the CPSC support nucleus along with the "Aconchego" ("Warmth") team, can increase the quality of life of breast cancer patients and that this also expresses satisfaction with the services provided by professionals and the health service. We still believe in the need for the continuity of this work and the adhesion of the professionals in the care and support to these patients with breast cancer. This study is an attempt to scrutinize support group functioning worldwide, and insights gained from this survey should be validated and further explored in future studies. In this era of personalized medicine, there is a clear need for improvement in support group functioning worldwide. 


\section{Acknowledgment}

We would like to thank all the patients who shared with us their experiences in breast cancer and allowed us to update to fight against this challenging disease, and everyone who participated directly or indirectly in the activities of the Cancer Patient Support Center (CPSC) and "Aconchego" ("Warmth").

\section{References}

1. Bray F, Ferlay J, Soerjomataram I, Siegel RL, Torre LA, et al. (2018) Global Cancer Statistics 2018: GLOBOCAN Estimates of Incidence and Mortality Worldwide for 36 Cancers in 185 Countries. Ca Cancer J Clin 68(6): 394424.

2. Machado SM, Sawada NO (2008) Evaluation of the quality of life of cancer patients on adjuvant chemotherapy. Text Context Enferm 17(4): 750-757.

3. Makluf ASD, Barra AA, Dias RC, Barros CP (2015) Quality of life among Brazilian women having undergone surgery for breast cancer: Validity and reliability of the Quality of life Questionnaire (EORTC QLQ-C30) and Breast Cancer Module (QLQ BR-23). Integr Cancer Sci Therapy 2(2): 107-111.

4. (2015) American Cancer Society Exercise Can Improve Breast Cancer Survivors' Quality of Life, USA.

5. Björneklett HG, Lindemalm C, Ojutkangas ML (2012) A randomized controlled trial of support group intervention on the quality of life and fatigue in women after primary breast cancer treatment. Support Care Cancer 20(12): 3325-3334.

6. Tamagawa R, Li Y, Gravity T (2015) Deconstructing therapeutic mechanisms in cancer support groups: do we express more emotion when telling stories directly to each other? J Behav Med 38(1): 171-182.
7. Sternfeld B, Lee IM (2008) Physical activity and cancer: the evidence, the issues, and challenges. In LEE IM (edn.); Physical activity and health epidemiologic methods and studies. Oxford University Press, New York, USA.

8. Juvet LK, Thune I, Elvaas IKO (2017) The effect of exercise on fatigue and physical functioning in breast cancer patients during and after treatment and at six months follow-up: The meta-analysis. Breast 33: 166-177.

9. Makluf ASD, Barra AA, Figueiredo EM, Silva GR, Ribeiro RFR, (2018) Influence of physical activity on the quality of life of breast cancer patients. BJSTR 10(3): 1-4.

10. Gabel M, Hilton NE, Nathanson SD (1997) Multidisciplinary breast cancer clinics. Do they work? Cancer 79(12): 2380-2384.

11. Butow P, Harrison JD, Choy ET (2007) Health professional and consumer views on involving breast cancer patients in the multidisciplinary discussion of their disease and treatment plan. Cancer 110(9): 19371944.

12. Choy ET, Chiu A, Butow P (2007) A pilot study to evaluate the impact of involving breast cancer patients in the multidisciplinary discussion of their disease and treatment plan. Breast 16(2): 178-189.

13. Santos FS (2009) Thanatology - The science of education for life. In: Palliative care - discussing life, death and dying. São Paulo.

14. Ruhstaller T, Roe H, Thurlimann B, Nicoll JJ (2006) The multidisciplinary meeting: An indispensable aid to communication between different specialities. Eur J Cancer 42(15): 2459-2462.

15. Amir Z, Scully J, Borrill C (2004) The professional role of breast cancer nurses in multi-disciplinary breast cancer care teams. Eur J Oncol Nurs 8(4): 306-314.

\section{ISSN: 2574-1241}

DOI: $10.26717 / B J S T R .2018 .12 .002187$

Alexandre de Almeida Barra. Biomed J Sci \& Tech Res

(C) (P) This work is licensed under Creative

Submission Link: https://biomedres.us/submit-manuscript.php
Commons Attribution 4.0 License

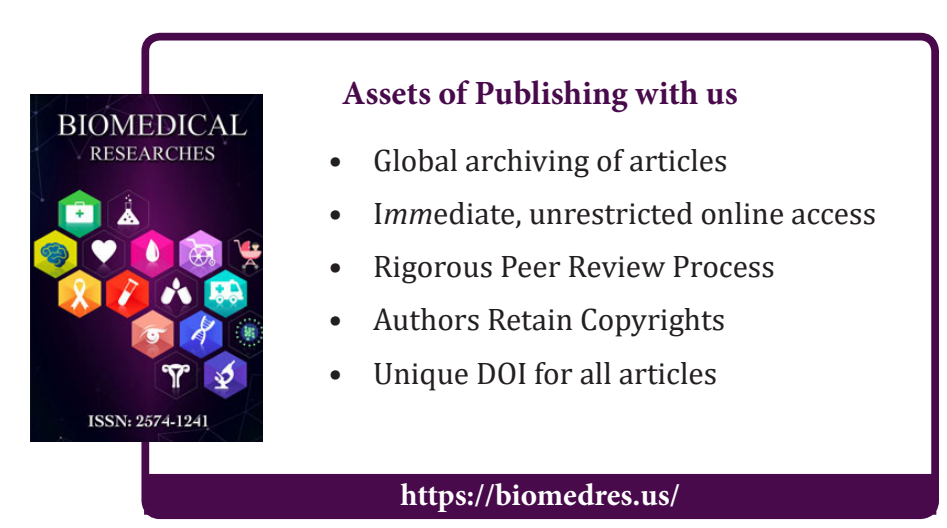

